\title{
Cardiovascular changes during acute episodic repetitive hypoxic and hypercapnic breathing in rats
}

\author{
M. Bakehe, J.L. Miramand, B. Chambille, Cl. Gaultier, P. Escourrou
}

Cardiovascular changes during acute episodic repetitive hypoxic and hypercapnic breathing in rats. M. Bakehe, J.L. Miramand, B. Chambille, Cl. Gaultier, P. Escourrou. @ERS Journals Ltd 1995.

ABSTRACT: It has been shown that chronic repetitive ambient hypoxia, simulating pulmonary gas disturbances observed in apnoea, leads to systemic hypertension in rats. However, the relative roles of hypoxia (HO), hypercapnia (HC), gas stress and vigilance on the cardiovascular changes have not yet been demonstrated.

The aim of this study was to investigate the acute haemodynamic changes observed during the repetitive inhalation of various gas mixtures in rats for $\mathrm{HO}$ alone and $\mathrm{HO}$ $+\mathrm{HC}$, and to analyse the effects of vigilance and of the stress of gas administration.

We studied 6 unanaesthetized Wistar rats chronically instrumented with an aortic catheter. Nitrogen, nitrogen $+\mathrm{CO}_{2}$ mixtures and compressed air were randomly administered in a Plexiglass chamber for $10 \mathrm{~s}$ and then flushed by compressed air for $20 \mathrm{~s}$. Two cycles were repeated every min for 10 to $12 \mathrm{~min}$. The inhaled gas fractions $\left(\mathrm{FI}_{1}, \mathrm{O}_{2}, \mathrm{FI}_{1}, \mathrm{CO}_{2}\right)$ were monitored by $\mathrm{O}_{2}$ and $\mathrm{CO}_{2}$ analysers. Blood pressure (BP) was measured by a P23XL transducer. The blood gases were analysed by a 1306 IL meter.

In control experiments, with compressed air alone, there were no significant acute changes in heart rate (HR) and BP. During HO there were no changes in HR or $B P$ at $F 1, O_{2}$ values from $0.05-0.14$, whilst at $F 1, O_{2}$ values from $0-0.05$ systolic blood pressure (SBP) rose significantly $(+25.3 \pm 25.7(\mathrm{sD}) \mathrm{mmHg})$ and $\mathrm{HR}$ decreased $(-93.8 \pm 124.1 \mathrm{bpm})$. During HOHC, SBP rose $(+35.1 \pm 26.4 \mathrm{mmHg})$ and HR decreased $(-139.3 \pm 75.7 \mathrm{bpm})$, significantly more than in $\mathrm{HO}$ alone. SBP was linearly correlated with $\mathrm{Pa}_{2} \mathrm{O}_{2}$ during $\mathrm{HO}(\mathrm{r}=0.53)$ and also during $\mathrm{HOHC}(\mathrm{r}=0.44)$ and was not directly related to $\mathrm{Pa}_{1} \mathrm{CO}_{2}$ which has, nevertheless, an additive effect to HO. SBP rose with each challenge significantly more when the rats were awake than when asleep (behavioural sleep).

We conclude that in this acute repetitive inhalation model, the rise in SBP is not related to gas stress or to $\mathrm{Pa}_{\mathrm{a}} \mathrm{CO}_{2}$ but to a decrease in $\mathrm{Pa}, \mathrm{O}_{2}$ and is enhanced by wakefulness.

Eur Respir J., 1995, 8, 1675-1680.
Physiology Laboratory, School of Medicine, Paris-Sud University, F-94276 KremlinBicêtre, France.

Correspondence: M. Bakehe Laboratoire de Physiologie

Faculté de Médecine

63 rue Gabriel PERI

F-94276 le Kremlin-Bicêtre (France).

Keywords: Blood pressure

hypercapnia

hypoxemia

rats

sleep apnoea syndrome vigilance

Received: April 31995

Accepted after revision August 81995
Sleep Apnoea Syndrome (SAS) is the consequence of repetitive obstructive apnoea due to the collapse of the upper airways. These apnoea are responsible for repetitive hypoxaemia, sleep disruptions and blood pressure swings. The acute postapnoeic blood pressure elevation is correlated with the degree of hypoxia during apnoea [1]. HEDNER et al. [2] have suggested that hypoxaemia and sympathetic activity mediate blood pressure changes in SAS. However, prevention of hypoxia during obstructive sleep apnoea by supplementary oxygen did not decrease the systemic pressure rise associated with the termination of apnoea $[3,4]$. Another potential mechanism which may contribute to the rise in blood pressure in sleep apnoea is arousal, which is usual at apnoea termination. It has been shown that arousal from normal sleep raises blood pressure to a level similar to that seen at the resumption of breathing after sleep apnoea [5].
The role of acute episodic hypercapnia has not been evaluated up to now, although hypercapnia is known to be a potent arousing stimulus and is increased during long apnoeas in humans [6]. Each of these three mechanisms may participate in cardiovascular changes associated with acute SAS. This study examines the relationship between hypoxia, hypercapnia, stress and vigilance on the haemodynamic changes observed during simulated repetitive apnoeas in rats, in order to define the mechanisms of these acute haemodynamic changes in SAS.

\section{Materials and methods}

Six Wistar male rats (400-500 g) were anaesthetised using sodium pentobarbital ( $30 \mathrm{mg} \cdot \mathrm{kg}^{-1}$ i.p.). Except during the experimental periods, the animals were housed in their usual cages where they ate and drank water ad libitum. 


\section{Inhalation chamber}

Severe HO (SHO) was defined as fractional concentration of inspiratory $\mathrm{O}_{2} \mathrm{O}-0.05\left(\mathrm{FI}, \mathrm{O}_{2}\right)$, and mild $\mathrm{HO}(\mathrm{MHO})$ as $0.051-0.14 F \mathrm{I}_{2} \mathrm{O}_{2}$. Mild $\mathrm{HOHC}(\mathrm{MHOHC})$ and severe HOHC (SHOHC) were similarly defined from fractional concentration of inspiratory $\mathrm{CO}_{2}\left(F \mathrm{I}, \mathrm{CO}_{2}\right)$ ranges. The inhalation chamber was custom made in our laboratory (fig. 1). The animal was housed in a cylindrical Plexiglass chamber (inner diameter: $92 \mathrm{~mm}$; length: $320 \mathrm{~mm}$; total volume: $1,993 \mathrm{~cm}^{3}$ ) during daytime for 1-2 hours. The gases (ambient air, $\mathrm{N}_{2}(100 \%), \mathrm{N}_{2}(95 \%)+\mathrm{CO}_{2}(5 \%)$ ) were distributed in the inhalation chamber by manual valves. The animal received a turbulent flow of gases across a filtration device. The rat was totally free in the chamber. Two openings allowed sampling of the chamber gas for analysis of $\mathrm{O}_{2}$ and $\mathrm{CO}_{2}$ fractions (Gauthier, France), (Datex Normocap, FIN) and a catheter allowed blood pressure measurement.

\section{Catheterisation}

At least 2 days before the experiment, a PE 10 catheter (Portex, France) in PE 50 (Biotrol, France) was placed in the abdominal aorta via a femoral artery, tunnelled under the skin of the back and coming out at the neck in the chronically instrumented conscious rats. Blood pressure was measured by a P23XL Gould transducer (Gould Electronics, USA) connected to a Gould pressure Processor (Gould Electronics, USA). Blood pressure, heart rate, $\mathrm{Fi}_{\mathrm{i}, \mathrm{O}_{2}}$ and $\mathrm{Fi}, \mathrm{CO}_{2}$ were recorded on a Data Management System (DMS) 1000 (Graphtec, USA).

\section{Blood gas measurement}

Blood was sampled from the aortic catheter between the 7 th and 8 th min during each recording session. A

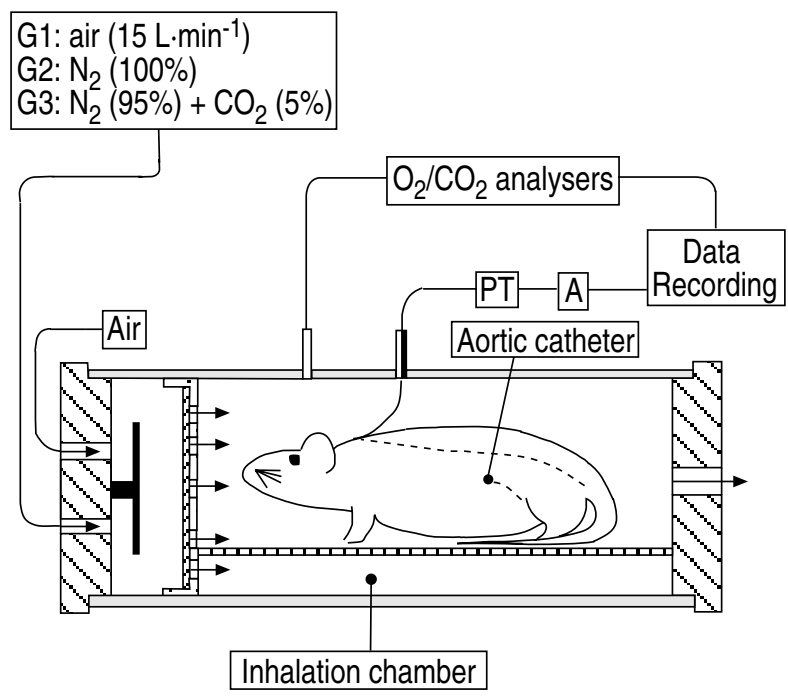

Fig. 1. - Experimental set up. PT: pressure transducer; A; amplifier; $\mathrm{G}$ : gases or gas mixtures. sample of $150 \mu \mathrm{L}$ of blood was removed in a heparinised glass capillary tube which took about $1 \mathrm{~min}$ to be completed. Blood gases were analysed by an IL 1306 pH/blood gas analyser (Instrumentation Laboratory, Italy).

\section{Protocol}

Once a day, before the first recording session, the animal was acclimatised to the inhalation chamber. The test gas was randomly chosen $\left(\mathrm{N}_{2}, \mathrm{~N}_{2}+\mathrm{CO}_{2}\right.$ and compressed air) for between 10-12 min periods. During each period the test gas was administered in the inhalation chamber for $10 \mathrm{~s}$ then flushed by compressed air for 20 s. Two cycles were repeated every min for 10-12 min. Sleep status was evaluated by the analysis of behavioural sleep to differentiate between wakefulness and sleep status (quiet sleep and active sleep periods were added together).

\section{Data analysis}

For each cycle, values of heart rate (HR), systolic blood pressure (SBP) and diastolic blood pressure (DBP) have been measured on the recording by visual averaging over the whole part of the cycle in air breathing $(20 \mathrm{~s})$ and at the maximum of the response during the $10 \mathrm{~s}$ of gas challenge. For each variable, the difference between the maximal response and the air breathing average has been computed for each cycle. These differences have been averaged for 12-14 cycles in the same experimental period for each rat. Then, these differences were averaged for all rats exposed to an identical challenge.

\section{Statistical methods}

The results are expressed as mean $\pm \mathrm{SD} ; \mathrm{p}<0.05$ was considered as significant. The effects of different levels of hypoxia and hypoxia + hypercapnia on the variations in SBP, DBP and HR were compared by two-sided paired t-test. Regression analysis between $\mathrm{SBP}$ and $\mathrm{Pa}, \mathrm{O}_{2}$ or $P \mathrm{a}, \mathrm{CO}_{2}$ was performed using the least squares method. $\mathrm{BP}$ and HR were compared between sleeping (behavioural sleep) and waking animals by two-way analysis of variance (ANOVA) with gas challenge and vigilance as factors. Mean values have been compared by t-test using Bonferroni correction for multiple comparisons. $\mathrm{Pa}, \mathrm{O}_{2}$ and $\mathrm{Pa}, \mathrm{CO}_{2}$ were compared using two-sided paired t-test between each gas challenge.

\section{Results}

\section{Typical tracings}

The BP and HR changes stabilised after 2-3 min of challenge and remained so during the 10-12 min period. Figure 2 illustrates a recording for the same animal in 

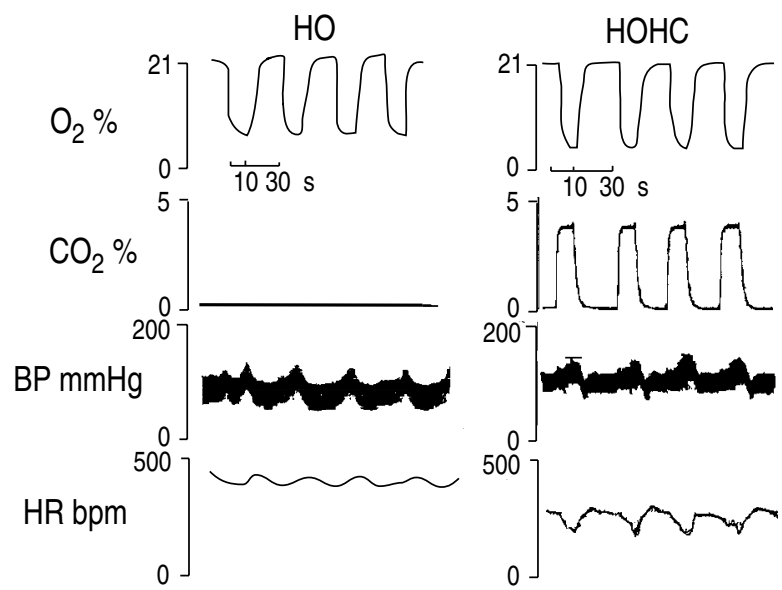

Fig. 2. - Typical tracings illustrating a recording for the same animal in $\mathrm{HO}$ (hypoxia alone) and HOHC (hypoxia + hypercapnia). There was an increase in blood pressure (pressor response) and a decrease in HR (bradycardia) diminished during the $10 \mathrm{~s}$ of the gas challenge during hypoxia (left panel). The HR and BP changes were greater when hypercapnia was added to HO (right panel). BP: blood pressure; HR: heart rate.

HO (hypoxia alone) and HOHC (hypoxia + hypercapnia). There was an increase in blood pressure (pressor response) and a decrease in HR (bradycardia) during the $10 \mathrm{~s}$ of the gas challenge during hypoxia (left panel). The HR and BP changes were greater when hypercapnia was added to HO (right panel).

\section{Effect of compressed air}

Four rats were studied. There were no significant differences in SBP values between the baseline (131.8 \pm 39.5 $\mathrm{mmHg})$ and compressed air $(131.9 \pm 13.4 \mathrm{mmHg})$. Similarly, there was no significant change in HR $(319.7 \pm 4.2$ bpm vs. 317.6 \pm 45.4 bpm respectively).

\section{Blood gases (table 1)}

Ambient hypoxia (HO) led to hypoxaemia and hypocapnia in the waking and sleeping states. $P \mathrm{a}, \mathrm{O}_{2}$ was lower and $\mathrm{Pa}_{\mathrm{a}} \mathrm{CO}_{2}$ higher during sleeping $(\mathrm{p}<0.05)$. In $\mathrm{HOHC}$,
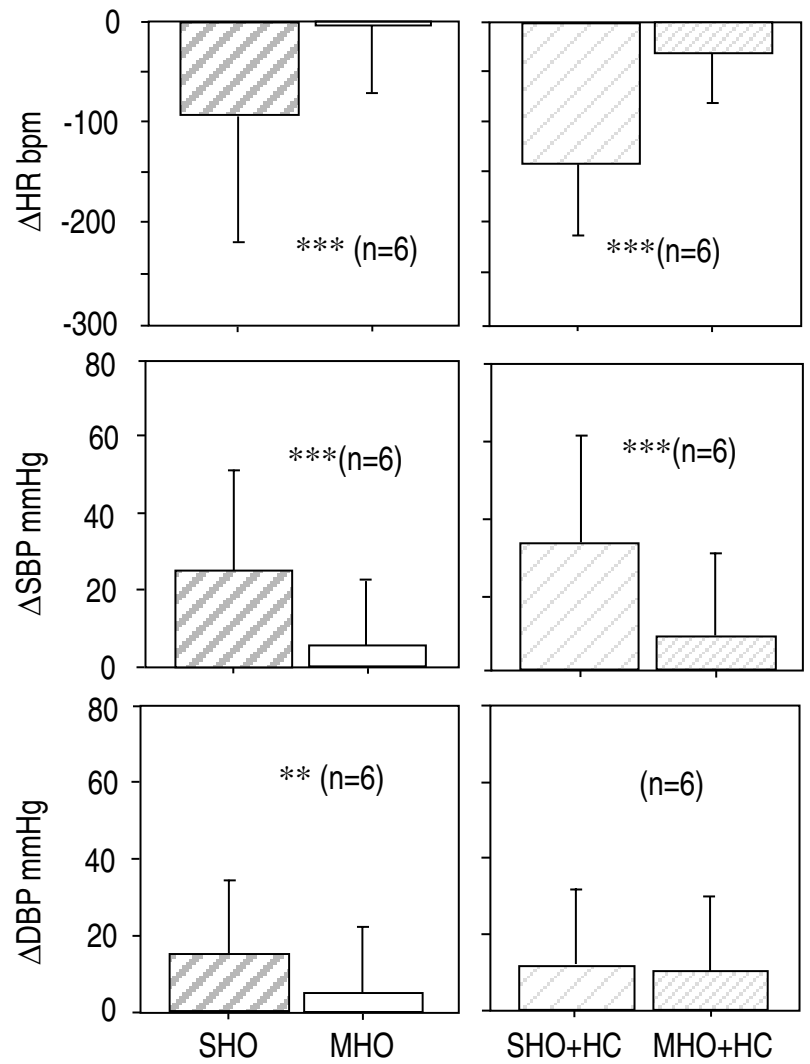

Fig. 3. - Variations in heart rate and blood pressure. SHO: severe hypoxia, 0-5\% $\mathrm{O}_{2} / 0 \% \mathrm{CO}_{2}$; MHO: mild hypoxia, 5.1-14\% $\mathrm{O}_{2} / 0 \%$ $\mathrm{CO}_{2}$; $\mathrm{SHO}+\mathrm{HC}$ : severe hypoxia + hypercapnia, $0-5 \% \mathrm{O}_{2} / 5-3 \% \mathrm{CO}_{2}$; $\mathrm{MHO}+\mathrm{HC}$ : mild hypoxia + hypercapnia, $5.1-14 \% \mathrm{O}_{2} / 2.9-1 \% \mathrm{CO}_{2}$; DPB: diastolic blood pressure; SPB: systolic blood pressure; HR: heart rate. **: $\mathrm{p}<0.01 ; * * *: \mathrm{p}<0.0001$ for comparison SHO vs. MHO and $\mathrm{SHO}+\mathrm{HC} v s$. MHO+HC.

$\mathrm{Pa}_{\mathrm{a}} \mathrm{CO}_{2}$ was identical to air during the waking state and was slightly lower in the sleeping state $(\mathrm{p}<0.05)$.

\section{Heart rate}

Six rats were studied during $\mathrm{HO}$ and $\mathrm{HOHC}$. HR decreased significantly more during severe $\mathrm{HO}(-93.8 \pm 124.1$ bpm) or severe HOHC $(-139.3+75.7 \mathrm{bpm})(\mathrm{p}<0.0001)$ than during mild $\mathrm{HO}(-3.1 \pm 67.8 \mathrm{bpm})$ or mild $\mathrm{HOHC}$ $(-28.5 \pm 52.0 \mathrm{bpm})$ (fig. 3). HR decreases more during $\mathrm{HOHC}$ compared to HO.

Table 1. - Blood gases in waking and sleeping animals during hypoxia $(\mathrm{HO})$ and hypercapnia $(\mathrm{HOHC})$.

\begin{tabular}{|c|c|c|c|c|c|}
\hline & \multirow[b]{2}{*}{$\begin{array}{c}\text { Air } \\
(n=6)\end{array}$} & \multicolumn{2}{|c|}{$\mathrm{HO}$} & \multicolumn{2}{|c|}{$\mathrm{HOHC}$} \\
\hline & & $\begin{array}{c}\text { Awake } \\
(\mathrm{n}=3)\end{array}$ & $\begin{array}{c}\text { Asleep } \\
(\mathrm{n}=3)\end{array}$ & $\begin{array}{c}\text { Awake } \\
(\mathrm{n}=3)\end{array}$ & $\begin{array}{c}\text { Asleep } \\
(\mathrm{n}=3)\end{array}$ \\
\hline \multicolumn{6}{|l|}{$P \mathrm{a}, \mathrm{O}_{2}$} \\
\hline torr & $86.3 \pm 7.1$ & $66.6 \pm 10.1^{*+}$ & $57.2 \pm 14.8^{*}$ & $78.5 \pm 15.7^{+}$ & $70.9 \pm 11.6 *$ \\
\hline $\mathrm{kPa}$ & $11.5 \pm 0.9$ & $8.9 \pm 1.3$ & $7.6 \pm 2.0$ & $10.4 \pm 2.1$ & $9.4 \pm 1.5$ \\
\hline \multicolumn{6}{|l|}{$P \mathrm{a}, \mathrm{CO}_{2}$} \\
\hline torr & $36.4 \pm 4.1$ & $31.3 \pm 2.8^{*+}$ & $33.9 \pm 7.1$ & $36.2 \pm 3.3^{+}$ & $33.4 \pm 3.1^{*}$ \\
\hline $\mathrm{kPa}$ & $4.8 \pm 0.5$ & $4.2 \pm 0.4$ & $4.5 \pm 0.9$ & $4.8 \pm 0.4$ & $4.4 \pm 0.4$ \\
\hline $\mathrm{pH}$ & $7.38 \pm 0.06$ & $7.40 \pm 0.07^{+}$ & $7.44 \pm 0.04 *$ & $7.38 \pm 0.01^{+}$ & $7.41 \pm 0.04$ \\
\hline
\end{tabular}

The values are mean \pm SD. $\left({ }^{+}\right)$denotes a significant difference $(\mathrm{p}<0.05)$ between waking and sleeping values. $(*)$ denotes a significant difference $(\mathrm{p}<0.05)$ between Air (Baseline) values and $\mathrm{HO}$ or $\mathrm{HOHC}$ values. 

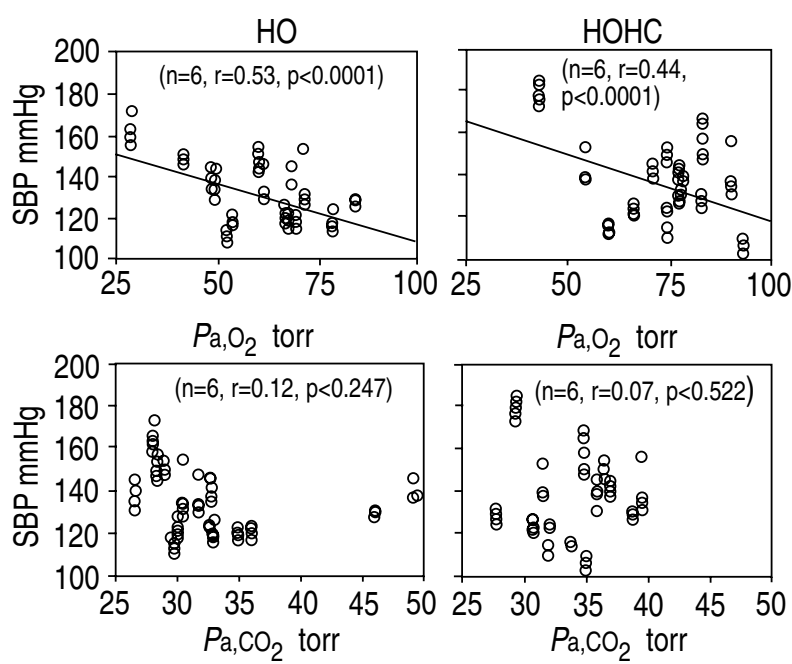

Fig. 4. - Correlations between SBP vs. $P \mathrm{a}, \mathrm{O}_{2}(\mathrm{HO}, \mathrm{HOHC})$ and $\mathrm{Pa}_{\mathrm{a}} \mathrm{CO}_{2}$ $(\mathrm{HO}, \mathrm{HOHC})$. $\quad P \mathrm{a}_{2} \mathrm{O}_{2}$ : arterial oxygen tension; $\mathrm{Pa}_{\mathrm{a}} \mathrm{CO}_{2}$ : arterial carbon dioxide tension. For further abbreviations see legend to figure 3 .

\section{Blood Pressure}

All the SBP increases were statistically significant at $\mathrm{p}<0.0001$ for severe $\mathrm{HO}(+25.3 \pm 25.7 \mathrm{mmHg})$ and severe $\mathrm{HOHC}(+35.1 \pm 26.4 \mathrm{mmHg})$ compared respectively to mild $\mathrm{HO}(+5.9 \pm 16.9 \mathrm{mmHg})$ and mild $\mathrm{HOHC}(+10.4 \pm 21.1$ $\mathrm{mmHg}$ ) (fig. 3). There was a significant difference between the SBP rise in severe and mild HO compared respectively to the SBP rise in severe and mild $\mathrm{HOHC}$ $(\mathrm{p}<0.001)$. DBP increase was significant in SHO compared to MHO $(\mathrm{p}<0.01)$

\section{Relationship between $\mathrm{SBP}$ and $\mathrm{Pa}_{2} \mathrm{O}_{2}$ and $\mathrm{Pa}_{a} \mathrm{CO}_{2}$}

Figure 4 shows the relationship between SBP during gas challenge and the corresponding values of $\mathrm{Pa}, \mathrm{O}_{2}$ and

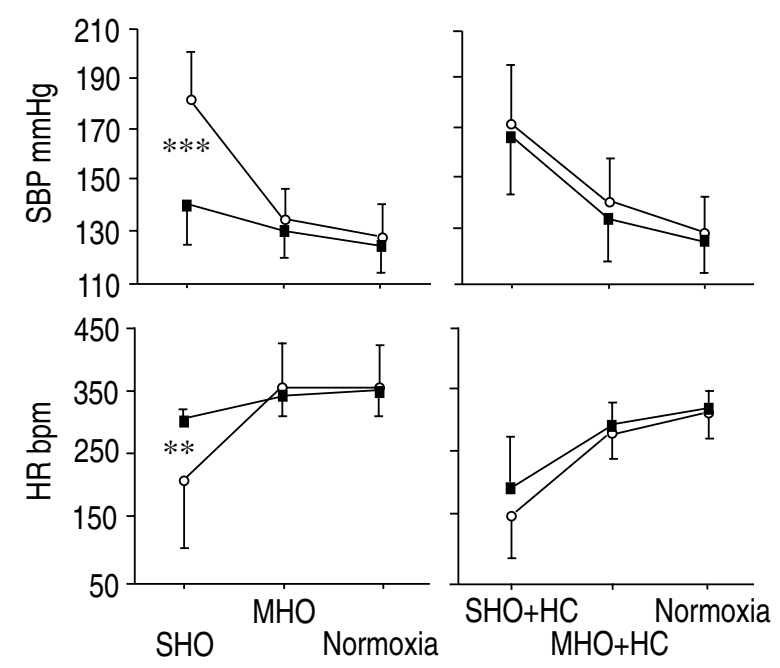

Fig. 5. - Effect of vigilance on SBP and HR. SHO: Severe hypoxia $0-5 \% \mathrm{O}_{2} / 0 \% \mathrm{CO}_{2}$; MHO: mild hypoxia 5.1-14\% $\mathrm{O}_{2} / 0 \% \mathrm{CO}_{2}$; $\mathrm{SHO}$ $+\mathrm{HC}$ : severe hypoxia + hypercapnia $0-5 \% \mathrm{O}_{2} / 5-3 \% \mathrm{CO}_{2} ; \mathrm{MHO}+$ $\mathrm{HC}$ : mild hypoxia + hypercapnia $5.1-14 \% \mathrm{O}_{2} / 2.9-1 \% \mathrm{CO}_{2}$; normoxia: $21 \% \mathrm{O}_{2}$. O: awake $(\mathrm{n}=3) ; \boldsymbol{\square}$ : behavioural sleep $(\mathrm{n}=3)$. $* *: \mathrm{p}<0.01$; $* * *: \mathrm{p}<0.0001$. For further abbreviations see legend to fig 3 .
$P \mathrm{a}, \mathrm{CO}_{2}$. There were significant correlations between SBP and $\mathrm{Pa}, \mathrm{O}_{2}$ in $\mathrm{HO}(\mathrm{r}=0.53 ; \mathrm{p}<0.0001)$ and in $\mathrm{HOHC}(\mathrm{r}=0.44$; $\mathrm{p}<0.0001$ ) with similar slopes but significantly different intercepts. There was no relationship between SBP and $\mathrm{Pa}_{\mathrm{a}} \mathrm{CO}_{2}$ in $\mathrm{HO}$ or in $\mathrm{HOHC}$.

\section{Effect of vigilance}

Three rats slept throughout the experiment (behavioural sleep) and three others remained awake. In $\mathrm{HO}$, all the SBP and HR changes were significantly higher during wakefulness than during sleep $(\mathrm{p}<0.001)$ (ANOVA). In $\mathrm{HOHC}, \mathrm{HR}$ was only slightly higher during sleep $(\mathrm{p}<0.06)$ (fig. 5).

\section{Discussion}

Our data confirms that acute repetitive periods of $\mathrm{HO}$ or acute HO combined with $\mathrm{HC}$ for 10-12 min significantly increase SBP and DBP, and decrease HR. The new findings in this study are that: 1) the control experiment to test the gas stress (compressed air) showed no difference for HR and SBP compared to their baselines; 2) the haemodynamic changes observed in this acute repetitive inhalation model in rats were higher when $\mathrm{HC}$ was superimposed by $\mathrm{HO} ; 3$ ) the increase in SBP and the moderate decrease in HR were enhanced by wakefulness during $\mathrm{HO}$.

In this acute inhalation model the gas stress is not responsible for the observed haemodynamic changes. This finding is in agreement with a recent study demonstrating that the chronic blood pressure of rats exposed for 5 weeks to episodic compressed air was unchanged [7].

The increases in SBP and DBP and the decreases in HR were significantly related to the level of hypoxia but not hypercapnia. However, the sampling for blood gas determination provided only averaged values for $1 \mathrm{~min}$, therefore, including two full cycles of gas challenge and compressed air flushing. In agreement with this finding, Stoohs and Guilleminault [8] demonstrated in five men with severe obstructive sleep apnoea, that mean blood pressure always increased during the obstructive period and that the changes in HR were correlated with the degree of hypoxaemia. In experimental models of repetitive airway obstruction in anaesthetised dogs, IwASE et al. [9] showed that the main factor in the increase in systemic arterial pressure during repetitive airway obstruction was hypoxaemia and that hypercapnia and acidosis had no significant effects. Increases in apnoeic and postapnoeic blood pressure correlate with the degree of hypoxia during apnoea [1]. Periods of 35 days of episodic hypoxia in rats, mimicking the episodic hypoxaemia of sleep apnoea in humans, cause a diurnal increase in mean blood pressure of $14 \mathrm{mmHg}$ [7]. The bradycardia that occurs during apnoea in adults has been found to be proportional to the degree of oxygen desaturation and the duration of apnoea [10]. BARKER et al. [11] demonstrated that oxygen administration during obstructive apnoea can attenuate bradycardia. However, in contrast to these data, the prevention of hypoxia during sleep apnoea syndrome 
by supplementary oxygen does not appear to blunt the elevation of systemic pressure associated with apnoea termination [3]. Furthermore, our model shows arterial blood pressure elevation during the hypoxaemic period of the apnoea whereas ALI et al. [3] gave BP values only during the resumption of breathing after the apnoea. The pressor response during apnoea may be due to hypoxaemia whilst the postapnoeic pressor response may have other origins such as an increase in venous return due to mechanical changes. In another study, Pelletier [12] showed, in dogs, that the pressor response to the stimulation of carotid chemoreceptors with hypoxic blood is augmented by hypercapnic acidosis. On the other hand, increasing $P \mathrm{a}, \mathrm{CO}_{2}$ by $1.4 \mathrm{kPa}$ in anaesthetised dogs increased arterial pressure only by about $5 \mathrm{mmHg}$ [13] when blood pressure increased more than $20 \mathrm{mmHg}$ during the obstructive period in sleep apnoea [1]. These results [3, $5,7]$ conflict with previous data $[1,8-10]$ and our finding showing the predominant role of hypoxaemia over hypercapnia in acute changes in SBP, DBP and HR. In our study, increases in SBP were higher with $\mathrm{HOHC}$ $(+35.1 \pm 26.4 \mathrm{mmHg})$ than with $\mathrm{HO}(+25.3 \pm 25.7 \mathrm{mmHg})$ and HR decreased more with HOHC, (severe, $-139.3 \pm 75.7$ bpm; mild, $-28.5 \pm 52.0 \mathrm{bpm}$ ) than HO (severe, $-93.8 \pm 124.1$ bpm; mild, $-3.1 \pm 67.8 \mathrm{bpm}$ ) (fig. 3 ). These results may be explained by the interaction of $\mathrm{CO}_{2}$ on the hypoxic response so that the magnitude of the $\mathrm{BP}$ rise with $\mathrm{HO}$ is shifted upwards by HC.

Another finding in our study is that the haemodynamic changes are significantly enhanced by wakefulness. Previous work by PINTO et al. [14] showed, in a porcine model of airway obstruction, that mean arterial pressure (MAP) increased by $5 \pm 2 \mathrm{mmHg}$ on arousal during nonrapid-eye-movement (NREM) sleep. However, during rapid-eye-movement (REM) sleep, MAP was increased fourfold $(22 \pm 2 \mathrm{mmHg})$ on arousal compared to NREM. Furthermore, it has been demonstrated that blood pressure increases are correlated with graded arousals in nonrapid-eye-movement (NREM) sleep [4, 5]. In our study, the SBP of waking animals was significantly increased $(\mathrm{p}<0.0001)$ in SHO compared to sleeping animals. The HR of sleeping animals decreased less, although significantly $(\mathrm{p}<0.001)$ compared to waking animals in $\mathrm{HO}$ (fig. 5).

The mechanisms by which hypoxaemia increases blood pressure and decreases HR are still the subject of debate. For blood pressure elevation, hypoxaemia may act through activating peripheral chemoreceptors which results in increases in systemic vascular resistance $[15,16]$. On the other hand, WALKER and BRIZZEE [17] showed that baroreflexes are important components in cardiovascular responses to both hypercapnic and hypoxic stimuli in conscious rats. Cardiac brady-arrhythmias are mediated by vagal activity [18] and bradycardia through arterial chemoreceptor action [19]. However, the local vascular effect of hypoxia is vasodilatory. This effect seems to depend on the vessel type [20]. The mechanism of this vasodilator action by hypoxia is not yet clear. In recent studies vasoregulators derived from the endothelium, including prostaglandins [21] and nitric oxide [21, 22] may be implicated. This suggests that
SAS may be associated with increased autonomic nervous system activity and endothelium derived activity.

The present acute, repetitive, inhalation model in rats, simulating gas changes observed during acute obstructive sleep apnoea in humans, may provide a new instrument for exploring and understanding the early mechanisms implicated in arterial hypertension associated with apnoea.

Acknowledgements: This study was supported by the Fondation de France (Contrat 91-5677) and School of Medicine, Paris XI University (EA 1820). Animal Research Agreement - 94184

\section{References}

1. Shepard JW. Gas exchange and hemodynamics during sleep. Med Clin N Am 1985, 69: 1243-1264.

2. Hedner J, Ejnell H, Carlsson J, Caidahl K. Consequences of increased sympathetic activity in sleep apnea. A pathogenetic mechanism for cardiovascular complications? Sleep 1990; 435-439.

3. Ali NJ, Fleetham JA, Stradling JA. The acute effects of continuous positive airway pressure and oxygen administration on blood pressure during obstructive sleep apnea. Chest 1992; 101: 1526-1232.

4. Ringler J, Basner RC, Shannon R, Schwartzstein R, Manning H, Weinberger SE, Woodrow Weiss J. Hypoxemia alone does not explain blood pressure elevation after obstructive apneas. J Appl Physiol 1990; 69(6): 2143-2148.

5. Davies RJO, Belt PJ, Roberts SJ, Ali NJ, Stradling JR. Arterial blood pressure responses to graded transient arousal from sleep in normal humans. J Appl Physiol 1993; 74(3): 1123-1130.

6. Phillipson EA, Sullivan CE. Arousal: the forgotten response to respiratory stimuli. Am Rev Respir Dis 1978; 118: 807-809.

7. Fletcher EC, Lesske CJ, Qian W, Miller CC, Unger T. Repetitive, episodic hypoxia causes diurnal elevation of blood pressure in rats. Hypertension 1992; 19(6 Pt 1): 555-561.

8. Stoohs R, Guilleminault C. Cardiovascular changes associated with obstructive apnea syndrome. J Appl Physiol 1992; 72(2): 583-589.

9. Iwase N, Kikuchi Y, Hida W, et al. Effects of repetitive airway obstruction on $\mathrm{O}_{2}$ saturation and systemic and pulmonary arterial pressure in anaesthetised dogs. Am Rev Respir Dis 1992; 146: 1402-1410.

10. Zwillich C, Devlin T, White D, et al. Bradycardia during sleep apnea: characteristics and mechanism. J Clin Invest 1982; 69: 1286-1292.

11. Baker BS, Fewell JE. Heart rate response to arousal and lung inflation following upper airway obstruction in lambs. Sleep 1988; 11(3): 233-241.

12. Pelletier CL. Circulatory responses to graded stimulation of the carotid chemoreceptors in the dog. Circ Res 1972; 31: 431-443.

13. Rothe CF, Maas-Moreno R, Flanagan AD. Effects of hypercapnia and hypoxia on the cardiovascular system: vascular capacitance and aortic chemoreceptors. Am J Physiol 1990; 259: H932-H939.

14. Pinto JMB, Garpestad E, Weiss JW. Hemodynamic changes associated with obstructive sleep apnea followed by arousal in a porcine model. J Appl Physiol 1993; 75(4): 1439-1443. 
15. Fletcher EC, Lesske J, Behm R, Miller III CC, Stauss $\mathrm{H}$, Unger T. Carotid chemoreceptors, systemic blood pressure, and chronic episodic hypoxia mimicking sleep apnea. J Appl Physiol 1992; 72(5): 1978-1984.

16. Downing SE, Mitchell JH, Wallace AG. Cardiovascular responses to ischemia, hypoxia, and hypercapnia of the central nervous system. Am J Physiol 1963; 204: 881-887.

17. Walker BR, Brizzee BL. Cardiovascular responses to hypoxia and hypercapnia in barodenervated rats. J Appl Physiol 1990; 68(2): 678-686.

18. Tilkian AG, Motta J Guilleminault C. Cardiac arrhythmias in sleep apnea. In: Liss AR (ed). Sleep Apnea Syndromes. New York 1978; pp. 197-210.
19. Masuyama S, Shinozaki T, Kohchiyama S, et al. Heart rate depression during sleep apnea depends on hypoxic chemosensitivity. Am Rev Respir Dis 1990; 14: 3942.

20. Daugherty RMJ, Scott JB, Dabney JM, Haddy FJ. Local effects of $\mathrm{O}_{2}$ and $\mathrm{CO}_{2}$ on limb, renal and coronary vascular resistances. Am J Physiol 1967; 213: 1102.

21. Vane JR, Anggard EE, Bottong RM. Regulatory functions of the vascular endothelium. N Engl J Med 1990; 323: 27-36.

22. Sun MK, Reis DJ. Evidence nitric oxide mediates the vasodepressor response to hypoxia in sino-denervated rats. Life Sci 1992; 50: 555-565. 